\title{
Endobronchial Treatment of Bronchial Carcinoid in the Elderly
}

\author{
Johannes M. A. Daniels ${ }^{1}$ - Ellen M. B. P. Reuling ${ }^{2}$ - C. Dickhoff $^{2}$
}

Published online: 19 August 2020

(C) The Author(s) 2020

\begin{abstract}
Purpose of the Review Although surgical resection is considered the gold standard of curative treatment for bronchial carcinoid, endobronchial treatment (EBT) can serve as a less invasive curative or palliative treatment in a selection of patients. It is unclear whether elderly patients with bronchial carcinoid should be treated in the same way as younger patients. In order to study the characteristics and treatment of elderly patients with bronchial carcinoid, we analyzed data from a cohort of patients that have been treated for bronchial carcinoid with EBT, surgical resection, or a combination of both. We used our existing database of patients referred for EBT and defined two groups of patients: $\geq 65$ and $<65$ years. We compared the characteristics, treatment, and causes of death between these groups. Successful EBT was defined as definitive treatment without signs of recurrence during follow-up with CT and bronchoscopy.

Recent Findings Thirty-five patients (19\%) were $\geq 65$ years. The incidence of atypical carcinoid was the same in both age groups (31\%). Thirty-six of 184 patients (20\%) were directly referred for surgical resection and $148(80 \%)$ underwent EBT. There was no significant difference in success of EBT between patients $<65$ years $(58 / 122,48 \%)$ and patients $\geq 65$ years $(15 / 26,58 \%)(p=$ 0.347). Complication rates were similar in both groups. After unsuccessful EBT, only $70 \%(14 / 20)$ of the elderly patients was operated, whereas $93 \%$ (85/91) of the patients $<65$ years was operated $(p=0.001)$. Disease specific mortality was $6 \%(2 / 35)$ in the group $\geq 65$ years and $2 \%(3 / 149)$ in the group $<65$ years.

Summary The incidence of atypical carcinoid is similar between the elderly and younger patients. Success rate and complication rate of EBT do not differ significantly between the age groups. After unsuccessful EBT, elderly patients were less likely to undergo surgical resection, which does not seem associated with excess disease specific mortality, although the number of events in this study is low.
\end{abstract}

Keywords Carcinoid $\cdot$ Neuro-endocrine tumor $\cdot$ Interventional bronchoscopy $\cdot$ Thoracic surgery $\cdot$ Elderly $\cdot$ Lung cancer

\section{Introduction}

Carcinoid tumors derive from pulmonary neuroendocrine cells and are part of the spectrum of neuro-endocrine tumors (NETs) $[1,2]$. Pulmonary NETs represent around $20 \%$ of all lung tumors and consist of small cell carcinoma (SCLC), large cell neuroendocrine carcinoma (LC-NEC), and typical (TC) and atypical

This article is part of the Topical Collection on Pulmonology and Respiratory Care

Johannes M. A. Daniels

j.daniels@amsterdamumc.nl

1 Department of Pulmonary Diseases, Amsterdam University Medical Center, Boelelaan 1117, 1081 HV Amsterdam, the Netherlands

2 Department of Surgery, Amsterdam University Medical Center, Boelelaan 1117, 1081 HV Amsterdam, the Netherlands carcinoid (AC) tumors. Carcinoid tumors have a more benign morphology, are less aggressive, and have a lower tendency to metastasize than SCLC and LC-NEC [3]. The incidence of bronchial carcinoid has increased in recent decades, probably due to a more prominent role of computed tomography in thoracic imaging and improved histopathology techniques [4]. The implementation of low-dose CT screening for lung cancer is likely to further increase the detection of subclinical carcinoid tumors [5]. Although surgical resection is considered the gold standard of curative treatment for both $\mathrm{TC}$ and $\mathrm{AC}$, endobronchial treatment (EBT) can serve as a less invasive curative or palliative treatment in a selection of patients. With this technique, several studies have shown excellent long-term outcome [6-11]. A recent systematic review by Reuling et al. evaluated all studies utilizing either surgical resection and/or EBT [12]. The authors concluded that centrally located, small intraluminal pulmonary carcinoids, without signs of metastasis, can be treated with minimally invasive alternatives such as endobronchial treatment or 
parenchyma sparing surgical resection. They also emphasized the low quality of the available evidence and advised that future clinical research should preferably consist of prospective trials. The best candidates for EBT are purely intraluminal carcinoid tumors with a diameter $<20 \mathrm{~mm}$ on CT scan [13••].

It is unclear whether elderly patients with bronchial carcinoid should be treated in the same way as younger patients. In an analysis of the European Association of Thoracic Surgeons (ESTS) Neuroendocrine Tumours Working Group, 1109 patients with typical bronchial carcinoid were studied [14]. Mortality was associated with increased age, male gender, the presence of previous malignancies, peripheral tumors, higher TNM stage, and higher ECOG performance score. Because age is apparently an important prognostic factor and because most bronchial carcinoids do not behave aggressively, it is important to question the therapeutic benefit of treatments with curative intent in elderly and frail patients. In an analysis of 4111 patients with biopsy specimen-proven lymph node-negative typical carcinoid tumor of the lung, it was shown that non-operative management was associated with an increased risk for disease-specific mortality when compared with lobectomy [15]. Importantly, in T1 tumors, 5 -year disease specific survival was still high (92\%) without any treatment, suggesting that observation of asymptomatic peripheral typical carcinoid tumors or endoscopic management of symptomatic central carcinoid tumors may be considered in high-risk patients.

At our institution we have a cohort of patients that have been treated for bronchial carcinoid with EBT, surgical resection, or a combination of both $[6,11]$. In order to study the characteristics and treatment of elderly patients we analyzed data from this cohort.

\section{Methods}

With Institutional review board approval (VU University Medical Center, IRB00002991), a cohort of patients with (suspected) bronchial carcinoids referred to our tertiary referral center for EBT was established between June 1991 and August 2015. Details of this patient cohort and the EBT technique have been described previously $[8,13 \cdot \bullet]$. In short, prior to treatment, all patients underwent a computed tomography (CT) scan of the chest and bronchoscopy as part of the routine workup. After informed consent, EBT was performed by experienced interventional pulmonologists and procedural data were registered. The procedure was planned based on information obtained from the chest $\mathrm{CT}$ scan and the bronchoscopy. Patients were excluded from EBT in the case of extraluminal growth, lymph node involvement, or evidence of multifocal/disseminated disease on CT scan. EBT was performed under general anesthesia. At the discretion of the interventional pulmonologist, removal of the carcinoid tissue was established using different ablative techniques, in the majority of patients, electro- or cryosurgery or mechanical debulking, or a combination of these techniques. After removal of the intraluminal lesion, the base was treated with cryotherapy in order to ablate any residual disease in the bronchial wall. The excised specimen was sent to the pathologist for histological diagnosis and classification. To detect residual disease, repeat bronchoscopy and $\mathrm{CT}$ scan were typically planned 6 weeks after EBT. In the absence of residual disease, patients were followed with CT scan and bronchoscopy annually. In patients with minimal residual disease EBT was repeated if deemed feasible. In patients with more extensive residual disease, surgical resection was performed. Patients who were medically inoperable or patients who refused operation were followed with CT scan and bronchoscopy and, in case of symptomatic bronchial obstruction (e.g. dyspnea, post obstruction pneumonia), bronchoscopic debulking was offered.

For the current analysis, we used our existing database and defined two groups of patients: $\geq 65$ and $<65$ years. We compared patient characteristics, treatment, and causes of death between these groups. Successful EBT was defined as definitive treatment without signs of recurrence during follow-up with CT and bronchoscopy.

\section{Statistical Analysis}

Data are presented as mean \pm standard deviation unless stated otherwise. Differences between groups were determined using the chi-square test or Fisher exact test for nominal variables.

\section{Results}

Table 1 shows the patient characteristics. Thirty-five patients $(19 \%)$ were 65 years or older. The mean age of the group < 65 years was 42.9 (SD, 13.5), and the mean age of the group $\geq$ 65 years was 70.4 (SD, 5.5). There was a slight female predominance in both groups. American Association for Anesthesiologists (ASA) physical status was higher in the elderly patients, with an ASA score of III in $43 \%$ of elderly patients versus $9 \%$ in younger patients. Median overall follow-up time was 72 months. The incidence of atypical carcinoid was the same in both age groups (31\%).

Figure 1 demonstrates the flow of patients through the treatment modalities. Thirty-six of 184 patients $(20 \%)$ were directly referred for surgical resection, of whom 33 were operated. The remaining 148 patients underwent EBT, which was successful in $49 \%(73 / 148)$. EBT was unsuccessful in 75 patients (51\%), 66 of whom underwent surgical resection $(88 \%)$. There was no significant difference in success of EBT between patients $<65$ years $(58 / 122,48 \%)$ and patients $\geq$ 65 years $(15 / 26,58 \%)(p=0.347)$. Complication rates were similar in both groups, $10 \%$ in patients $<65$ years and $11 \%$ in patients $\geq 65$ years. The most common complications were 
Table 1 Patient characteristics

\begin{tabular}{lcc}
\hline & $<65$ years $(n=149)$ & $\geq 65$ years $(n=35)$ \\
\hline Mean age (SD) (years) & $42,9(13.5)$ & $70,4(5.5)$ \\
Gender & & \\
Male & $58(39)$ & $16(46)$ \\
Female & $91(61)$ & $19(54)$ \\
Smoking history & & \\
Current & $20(13)$ & $7(20)$ \\
Former & $55(37)$ & $11(31)$ \\
Never & $68(46)$ & $1(40)$ \\
Unknown & $6(4)$ & $3(9)$ \\
Presenting symptoms & & \\
Pneumonia & $55(37)$ & $10(29)$ \\
Hemoptysis & $25(17)$ & $3(9)$ \\
Chronic cough & $30(20)$ & $7(20)$ \\
Dyspnea & $22(15)$ & $11(31)$ \\
Other & $11(7)$ & $2(6)$ \\
No symptoms & $6(3)$ & $2(6)$ \\
ASA physical status score & & $11(31)$ \\
I & $80(54)$ & $13(20)$ \\
II & $56(38)$ & $13(37)$ \\
III & $13(9)$ & \\
IV & $0(0)$ & \\
Histology & $102(69)$ & $(31)$ \\
Typical carcinoid & $16(1)$ & \\
Atypical carcinoid & & \\
Unclassified & & \\
\hline
\end{tabular}

Values are $n(\%)$ unless otherwise specified

ASA American Society of Anesthesiologists

peri-procedural bleeding, desaturation, and bronchospasm. In two patients, a bronchial stricture was noted during follow-up after electrocautery treatment.

When looking at patients in whom there was an indication for surgical resection (either directly or after non-curative EBT), we found that only $70 \%(14 / 20)$ of the elderly patients was operated, whereas in the group $<65$ years $93 \%$ (85/91) of the patients was operated $(p=0.001)$. Table 2 shows the reasons that surgery was not performed and the outcome of those patients. In the group < 65 years patient refusal was the most common reason for not performing surgery. One patient of 64 years was not operated because of comorbidity/frailty, but has been well for a long time. One patient was not operated because of synchronous nonHodgkin lymphoma, which was also the cause of death. In the group $\geq 65$ years, the most common reason not to operate was comorbidity/frailty and one patient of 65 years was deemed operable, but refused surgery. Four out of six patients died of another cause, one patient died after 159 months of an unknown cause and one patient is still alive and well with disease. Diseasespecific mortality was $6 \%(2 / 35)$ in the group $\geq 65$ years and $2 \%$ $(3 / 149)$ in the group $<65$ years.

\section{Discussion}

This study shows that in our cohort of patients referred for endobronchial treatment of carcinoid, $19 \%$ of patients is $\geq$ 65 years. When comparing patients who are $\geq 65$ years with those who are $<65$ years, the incidence of atypical carcinoid is similar (31\%), and success rate of EBT did not differ significantly (48\% for patients $<65$ years versus 58\% for patients $\geq 65$ years, $p=$ $0.347)$. After unsuccessful EBT, elderly patients were less likely to undergo surgery ( $70 \%$ versus $93 \%, p<0.001)$. In the elderly patients, the most common reason not to operate was comorbidity/frailty, while in the patients $<65$ years the most common reason was patient refusal. Disease-specific mortality was $6 \%(2 / 35)$ in the group $\geq 65$ years and $2 \%(3 / 149)$ in the group $<65$ years.

Although surgical resection is the most effective treatment, with excellent local control rate and lymph node staging, it makes sense that fewer elderly patients undergo surgery when compared with younger patients, because carcinoid tumors are usually less aggressive compared with other lung malignancies. Specifically, in elderly and frail patients, factors such as age, comorbidity, life expectancy, estimated therapeutic benefit, and patient preference should all be considered in clinical decision making. Even when it comes to non-small cell lung cancer (NSCLC), a much more
Fig. 1 Flow of patients through different treatment modalities

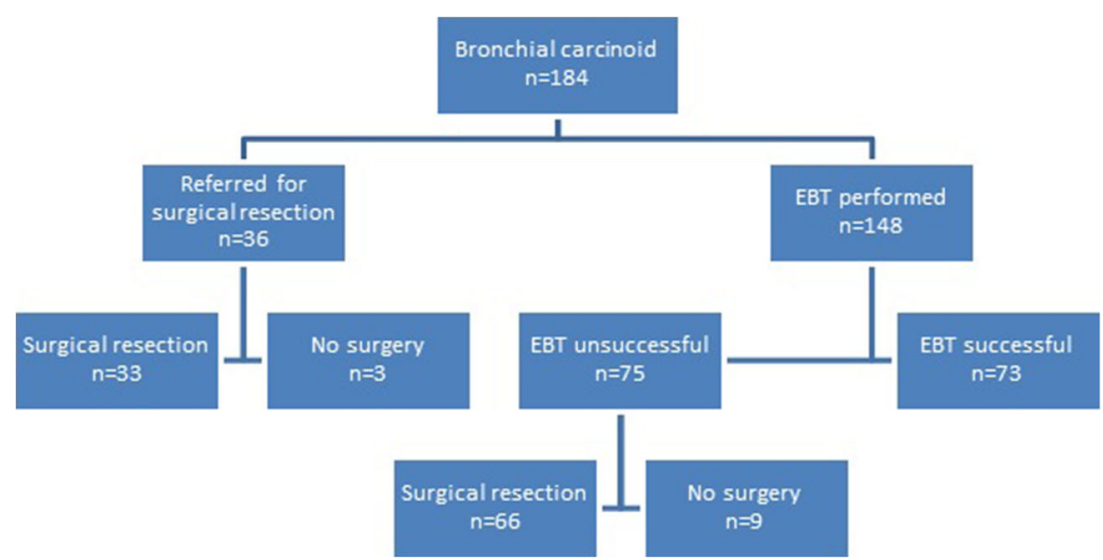


Table 2 Reasons for not performing surgery when indicated and outcome

\begin{tabular}{llll}
\hline Age (years) & Reason for not performing surgery & $\begin{array}{l}\text { Follow-up time } \\
\text { (months) }\end{array}$ & Status \\
\hline$<65$ years & & & \\
43 & Refused surgery, pneumonectomy 20 yrs. Later & 237 & Alive no disease \\
51 & Refused surgery & 98 & Alive with disease \\
51 & Refused surgery & 122 & Alive with disease \\
55 & Diagnosed with non-Hodgkin lymphoma & 140 & Dead other cause \\
61 & Refused surgery & 191 & Alive with disease \\
64 & Comorbidity/frailty & 100 & Alive with disease \\
$\geq 65$ years & & & \\
65 & Refused surgery & 3 & Dead other cause \\
74 & Comorbidity/frailty & 30 & Dead other cause \\
76 & Comorbidity/frailty & 90 & Dead other cause \\
77 & Comorbidity/frailty & 159 & Dead of unknown cause \\
79 & Comorbidity/frailty & 19 & Dead other cause \\
81 & Comorbidity/frailty & 52 & Alive with disease \\
\hline
\end{tabular}

aggressive disease than carcinoid, the elderly are less likely to undergo surgery. In 2001 in the Netherlands, 32\% of elderly patients $(\geq 75$ years) with early-stage NSCLC did not receive treatment with curative intent [16]. After the introduction of stereotactic body radiotherapy (SBRT) as a potential curative treatment of NSCLC in 2003, the proportion of Dutch elderly patients not receiving treatment with curative intent decreased to $19 \%$ by 2013 [17••]. In the Netherlands, SBRT is currently the prevailing treatment in octogenarians with stage I NSCLC [18••]. For bronchopulmonary carcinoid however, experience with SBRT as an alternative for surgical resection is limited. An analysis from the US National Cancer Database showed that 154 patients with cT1-2N0M0 typical bronchopulmonary carcinoid were treated with radiotherapy [19]. About $47 \%$ of the patients was 75 years or older, and $84(55 \%)$ were treated with SBRT, while the remainder were treated with conventionally fractionated radiotherapy. Propensity-matched Kaplan-Meier analysis revealed improved survival with lung SBRT (median: 66 vs 58 months; $p=0.034$ ) [19]. The patients in our cohort typically exhibit very central bronchial lesions, which might not be good candidates for stereotactic radiation due to their location in a large central airway and risk of lumen perforation [20]. In our institution, we do not currently use any form of radiotherapy for centrally located carcinoid tumors.

Endobronchial therapy might be the preferred modality for inoperable patients and patients with small intraluminal tumors. It also has the advantage that it can be repeated if required. Brokx et al. have reported on the long-term outcome after first-line bronchoscopic therapy in patients with bronchial carcinoid [8]. One hundred twelve patients were treated, with a median age of 47 years (range 16-77 years). Eighty-three patients (74\%) had typical carcinoid, and 29 (26\%) atypical carcinoid. EBT only was ultimately curative in $42 \%$ of the cases (47/112). Reuling at el. looked for predictors of successful EBT in a cohort of one hundred and twenty-five patients [13••]. Multivariate analysis showed that a tumor diameter $<15 \mathrm{~mm}$ and purely intraluminal growth on computer tomography (CT scan) were predictive of successful radical endobronchial treatment. The success rate for intraluminal tumors with a diameter $<20 \mathrm{~mm}$ was $72 \%$.

To further improve the treatment of bronchial carcinoid, especially in frail patients in whom the balance between overtreatment and under treatment is tight, biomarkers could be particularly useful. Recently, CD44 and orthopedia homeobox (OTP) protein expression have shown promise as prognostic biomarkers in pulmonary carcinoid. OTP is a homeodomain-containing transcription factor that mainly plays a role in the development of neuroendocrine cell lineages in the hypothalamus and in the differentiation of neuroblasts [21, 22]. CD44 seems to exhibit tumor suppressive effects by promoting apoptosis, but on the other hand seems to be involved in epithelial-to-mesenchymal transition and in promoting cell survival, and not surprisingly has been associated with both favorable as well as poor prognosis in different tumor types [23-25]. Swarts et al. studied mRNA expression levels of CD44 and OTP in 56 frozen pulmonary carcinoid specimens and CD44 and OTP protein expression in 292 pulmonary carcinoids [26]. They found that low transcriptional as well as low protein expression levels are strongly associated with a poor long-term survival rate of pulmonary carcinoid patients. If additional studies confirm that these markers can indeed reliably separate carcinoid with a favorable prognosis from carcinoids with a poor prognosis, they could be used to determine the most suitable treatment and follow-up strategy.

In conclusion, our cohort shows that the incidence of atypical carcinoid is similar between the elderly and younger patients. Furthermore, success rate and complication rate of EBT do not differ significantly between the age groups. After unsuccessful EBT, elderly patients are less likely to undergo surgery, which does not seem associated with excess disease specific mortality, although the number of events in this study 
is low. Treatment and follow-up of elderly patients with bronchopulmonary carcinoid may be improved by further study and implementation of some promising biomarkers.

\section{Compliance with Ethical Standards}

Conflict of Interest The authors declare that they have no conflict of interest.

Human and Animal Rights This article does not contain any studies with human or animal subjects performed by any of the authors.

Open Access This article is licensed under a Creative Commons Attribution 4.0 International License, which permits use, sharing, adaptation, distribution and reproduction in any medium or format, as long as you give appropriate credit to the original author(s) and the source, provide a link to the Creative Commons licence, and indicate if changes were made. The images or other third party material in this article are included in the article's Creative Commons licence, unless indicated otherwise in a credit line to the material. If material is not included in the article's Creative Commons licence and your intended use is not permitted by statutory regulation or exceeds the permitted use, you will need to obtain permission directly from the copyright holder. To view a copy of this licence, visit http://creativecommons.org/licenses/by/4.0/.

\section{References}

Papers of particular interest, published recently, have been highlighted as:

•- Of major importance

1. Travis WD. Pathology and diagnosis of neuroendocrine tumors: lung neuroendocrine. New York: Elsevier; 2014.

2. Filosso P. Clinical management of neuroendocrine tumors of the lung. In: Thoracic surgery clinics, volume 24-3. New York: Elsevier; 2014.

3. Tastepe AI, Kurul IC, Demircan S, Liman ST, Kaya S, Cetin G. Long-term survival following bronchotomy for polypoid bronchial carcinoid tumours. Eur J Cardio-Thoracic Surg. 1998;14:575-7.

4. Gustafsson BI, Kidd M, Chan A, Malfertheiner MV, Modlin IM. Bronchopulmonary neuroendocrine tumors. Cancer. 2008;113:5-21.

5. National Lung Screening Trial Research Team, Aberle DR, Adams AM, Berg CD, Black WC, Clapp JD, et al. Reduced lung-cancer mortality with low-dose computed tomographic screening. N Engl J Med. 2011;365:395-409.

6. Bertoletti L, Elleuch R, Kaczmarek D, Jean-Francois R, Vergnon JM. Bronchoscopic cryotherapy treatment of isolated endoluminal typical carcinoid tumor. Chest. 2006;130:1405-11.

7. Boyaci H, Cortuk M, Gul S, Tanriverdi E, Ozgul MA, Dincer HE, et al. Results of bronchoscopic excision in typical carcinoid tumors of the lung in Turkey. Medicinski Glasnik. 2017;14:61-6.

8. Brokx HA, Paul MA, Postmus PE, Sutedja TG. Long-term followup after firstline bronchoscopic therapy in patients with bronchial carcinoids. Thorax. 2015;70:468-72.

9. Cavaliere S, Foccoli P, Toninelli C. Curative bronchoscopic laser therapy for surgically resectable tracheobronchial tumors: personal experience. J Bronchol. 2002;9:90-5.

10. Dalar L, Ozdemir C, Abul Y, Sokucu SN, Karasulu L, Urer HN, et al. Endobronchial treatment of carcinoid tumors of the lung. Thorac Cardiovasc Surg. 2016;64:166-71.

11. Fruchter O, Fuks L, Amital A, Fox BD, Abdel Rahman N, Kramer MR. Longterm follow-up of flexible bronchoscopic treatment for bronchial carcinoids with curative intent. Diagn Ther Endosc. 2009.
12. Reuling EMBP, Dickhoff C, Plaisier PW, Bonjer HJ, Daniels JMA. Endobronchial and surgical treatment of pulmonary carcinoid tumors: a systematic literature review. Lung Cancer. 2019;134:85-95.

13.• Reuling EMBP, DickhoffC, Plaisier PW, Coupé VMH, Mazairac AHA, Lely RJ, et al. Endobronchial treatment for bronchial carcinoid: patient selection and predictors of outcome. Respiration. 2018;95(4):220-227. This paper showed that intraluminal carcinoid tumors of less than $20 \mathrm{~mm}$ in size can be treated bronchoscopically with good results.

14. Filosso PL, Guerrera F, Evangelista A, Welter S, Thomas P, Casado PM, et al. ESTS NETs-WG Steering Committee. Prognostic model of survival for typical bronchial carcinoid tumours: analysis of 1109 patients on behalf of the European Association of Thoracic Surgeons (ESTS) Neuroendocrine Tumours Working Group. Eur J Cardiothorac Surg. 2015 Sep;48:441-7.

15. Raz DJ, Nelson RA, Grannis FW, Kim JY. Natural history of typical pulmonary carcinoid tumors: a comparison of nonsurgical and surgical treatment. Chest. 2015;147:1111-7.

16. Haasbeek CJ, Palma D, Visser O, Lagerwaard FJ, Slotman B, Senan S. Early-stage lung cancer in elderly patients: a populationbased study of changes in treatment patterns and survival in the Netherlands. Ann Oncol. 2012;23:2743-7.

17.• Driessen E, Detillon D, Bootsma G, De Ruysscher D, Veen E, Aarts $\mathrm{M}$, et al. Population-based patterns of treatment and survival for patients with stage I and II non-small cell lung cancer aged 65-74 years and 75 years or older. J Geriatr Oncol. 2019;10:547-54. After the introduction of stereotactic body radiotherapy (SBRT) as a potential curative treatment of NSCLC in 2003, the proportion of Dutch elderly patients not receiving treatment with curative intent, decreased to $19 \%$ by 2013.

18.• de Ruiter JC, Heineman DJ, Daniels JM, van Diessen J, Damhuis RA, Hartemink KJ. The role of surgery for stage I non-small cell lung cancer in octogenarians in the era of stereotactic body radiotherapy in the Netherlands. Lung Cancer. 2020;144:64-70. In the Netherlands, SBRT is currently the prevailing treatment in octogenarians with stage I NSCLC.

19. Singh D, Chen Y, Cummings MA, Milano MT. Inoperable pulmonary carcinoid tumors: local control rates with stereotactic body radiotherapy/hypofractionated $\mathrm{RT}$ with image-guided radiotherapy. Clin Lung Cancer. 2019;20(3):e284-90.

20. Kallstrom K, Nyman J, Baumann P, et al. Retrospective cohort study of bronchial doses and radiation-induced atelectasis after stereotactic body radiation therapy of lung tumors located close to the bronchial tree. Int J Radiat Oncol Biol Phys. 2013;87:590-5.

21. Acampora D, Postiglione MP, Avantaggiato V, Di BM, Vaccarino FM, Michaud J, et al. Progressive impairment of developing neuroendocrine cell lineages in the hypothalamus of mice lacking the Orthopedia gene. Genes Dev. 1999;13:2787-800.

22. Wang W, Lufkin T. The murine Otp homeobox gene plays an essential role in the specification of neuronal cell lineages in the developing hypothalamus. Dev Biol. 2000;227:432-49.

23. Ponta H, Sherman L, Herrlich PA. CD44: from adhesion molecules to signalling regulators. Nat Rev Mol Cell Biol. 2003;4:33-45.

24. Schmits R, Filmus J, Gerwin N, Senaldi G, Kiefer F, Kundig T, et al. CD44 regulates hematopoieticprogenitor distribution, granuloma formation, and tumorigenicity. Blood. 1997;90:2217-33.

25. Brown RL, Reinke LM, Damerow MS, Perez D, Chodosh LA, Yang J, et al. CD44 splice isoform switching in human and mouse epithelium is essential for epithelial-mesenchymal transition and breast cancer progression. J Clin Invest. 2011;121:1064-74.

26. Swarts DR, Henfling ME, Van Neste L, van Suylen RJ, Dingemans AM, Dinjens WN, et al. CD44 and OTP are strong prognostic markers for pulmonary carcinoids. Clin Cancer Res. 2013;19:2197-207.

Publisher's Note Springer Nature remains neutral with regard to jurisdictional claims in published maps and institutional affiliations. 